Sädhanä, Vol. 19, Part 1, February 1994, pp. 75-92. (C) Printed in India.

\title{
Legal counselling system
}

\author{
$M^{1}$ SHASHI, K V S V N RAJU ${ }^{1}$ and A LAKSHMINATH ${ }^{2}$ \\ ${ }^{1}$ Department of Computer Science \& Systems Engineering, and \\ ${ }^{2}$ Department of Law, Andhra University, Visakhapatnam 530003 , India
}

\begin{abstract}
Legal reasoning involves case analysis in statutory as well as real world perspectives. The impact of real world perspective on case analysis poses a serious challenge to knowledge engineers for building legal expert systems. A legal expert system intends to provide intelligent support to legal professionals. The proposed legal predictive system is an attempt to predict the most probable outcome of a case according to statutory as well as real world knowledge of the legal domain. The system accepts the current fact situation of a case and analyses it interactively with legal personnel. This work introduces a frame-like knowledge structure, LATTICE, with two-dimensional attributes. This paper contains a detailed discussion on artificial intelligence-based case analysis of theft cases in a real world perspective.
\end{abstract}

Keywords. Legal reasoning; artificial intelligence; legal predictive system; legal expert systems.

\section{Introduction}

One of the basic principles of justice is that 'Justice delayed is justice denied'. It is from this that the Supreme Court of India has carved out the fundamental right to speedier trial from article 21 of the Constitution of India. The present adjudication process requires transformation in view of the high cost of legal services, baffling complications in existing procedures and frustrating delays in securing justice. Formal adjudication should be more of a last resort than it has been in the past. In recent times, efforts have been made to develop alternate adjudication models in the form of Lok Adalats, Nyaya Panchayats etc. In this context, the authors feel that alternate adjudication machinery can be augmented with modern computers for a greater extent of openness and accessibility thus lending credibility to the dependence of both government and people on these modes of alternate adjudication machinery.

Automation in the legal world was first proposed (Mehl 1958, pp. 755-79) at an International Symposium on "Mechanisation of Thought Processes" held at the National Physical Laboratory in Teddington, London. Law machines were classified by him into two types: documentary machines and consultation machines. Documentary machines are meant for legal information retrieval operations such as storing/ retrieving legal provisions and supporting as well as opposing precedents relevant to the given case. A program FLITE (Finding Legal Information Through Electronics), 
was developed in 1964 as the earliest full text retrieval system for the US Air Force. LEXIS and WESTLAW (Hafner 1987, pp. 35-42) are some of the recent commercial systems offering interactive retrieval through terminals at the customer's office. Intelligent support cannot be provided for the user while retrieving the precedents owing to the text matching (keyword search) technique followed in these systems. Hafner (1987, pp. 35-42) proposed an AI-based conceptual retrieval system using individual case frames so that search for relevancy can be made based on a concept of the case rather than text matching of certain keywords. Considerable research work has thus been carried out and significant developments have taken place in the area of documentary machines.

However, no such significant progress can be claimed to have been made in the area of consultation machines which are meant for giving legal advice. The HYPO system developed by Rissland and Ashley (Ashley \& Rissland 1988; Ashley 1991) during the 1980s aims at helping an attorney to analyse a new case in the light of relevant precedents (refer appendix $A$ for legal terms), and accordingly generate outlines of arguments for both plaintiff and defendant. The JUDGE system, developed in the late 80 s by Bain (Srivastava 1991) proposed modelling the sentencing ability of judges. This system identifies the most similar precedent according to a set of salient features and suggests a commensurate sentence for being awarded in the case on hand. These two systems have been the most widely accepted legal consultation systems to date. But these and similar other consultation systems are oriented towards precedents and are based on a case-based reasoning paradigm.

A precedent can either suggest judgement appropriate to cases with similar current fact situation or it can point to an apt case-law to solve a particular technical ambiguity. These two aspects of the precedent are to be dealt with separately since the first aspect provides only the guidelines whereas the second provides the case-law that is binding on lower courts. The first aspect is emphasised in systems like HYPO whereas the second aspect is considered in systems like JURIX (Srivastava 1991) and Gardner's legal reasoning system (Gardner 1987). Gardner's approach suggests that the case be analysed keeping in view statute as well as relevant case-laws. This system aims at giving decisions for 'easy' cases, while the 'hard' cases, cases which can be argued in either way by a competent lawyer, are left undecided. McCarthy's TAXMAN project (McCarthy 1980) models deductive legal reasoning based on statute. The control strategy of legal systems determines the applicability of those systems to various fields of legal domain - HYPO suits trade secret misappropriation. TAXMAN models the taxation of corporate reorganisation. Gardner's system deals with formation of contracts by offer and acceptance. However, for certain other legal fields, legal reasoning involves analysing the case through a real world perspective also. Along with the statutory rules, various heuristics imposed by culture, region, conventions and the experience of judges are also to be considered while making the decision. Given the case proceedings/current fact situation a highly structured legal reasoning system to analyse the case and thereby predict the most probable judgement based on the statute and discretion of the judge is proposed in this paper. It is hoped that the proposed legal counselling system will be of use to our society in the following ways.

(1) The system, by its ability to predict in advance the most probable outcome in a given case, will enable individual clients to decide about the advisibility or otherwise of entering into a legal dispute in a given situation. This in turn will lead to reduced workload on the considerably over-burdened courts. 
(2) The system, through its ability to estimate the effect of each individual fact on the judicial decision (by simulating the judgement with altered current fact situations) can aid legal practitioners and criminal investigators in discharging their professional duties more effectively and efficiently.

(3) The system, by providing an integrated view of the case through the highly structured representation of the current fact situation of the case, can be helpful to judges in taking faster decisions thereby mitigating the hardship caused to the litigant public by delayed justice, the bane of the present judicial system.

(4) The system can resolve petty litigations among people who cannot afford the money and the time required in the regular court proceedings, thus providing a computerised alternate adjudication system.

(5) Based on the model proposed, a generalised system can be developed by drawing on the expertise of several meritorious judges, which in turn can be used to check the correctness of a specific judgement, so that the case may be reconsidered if necessary.

\section{Proposed legal system}

The proposed system depicted in figure 1 is a legal counselling system that accepts the current fact situation of the case from a legal practitioner and interactively proceeds to analyse the case based on statute and real world information. Processing of a case in a real world perspective demands interactive case analysis. This system aims at predicting the most probable judgement. It has to process the following three types of legal information regarding a case.

(1) Technical information consists of particulars of sections of the relevant act invoked in dealing with the case, i.e. the ingredients and evidence level at which each of the ingredients has been established. This information regarding a specific case can be represented as an instance of the section's decision lattice (D-lattice).

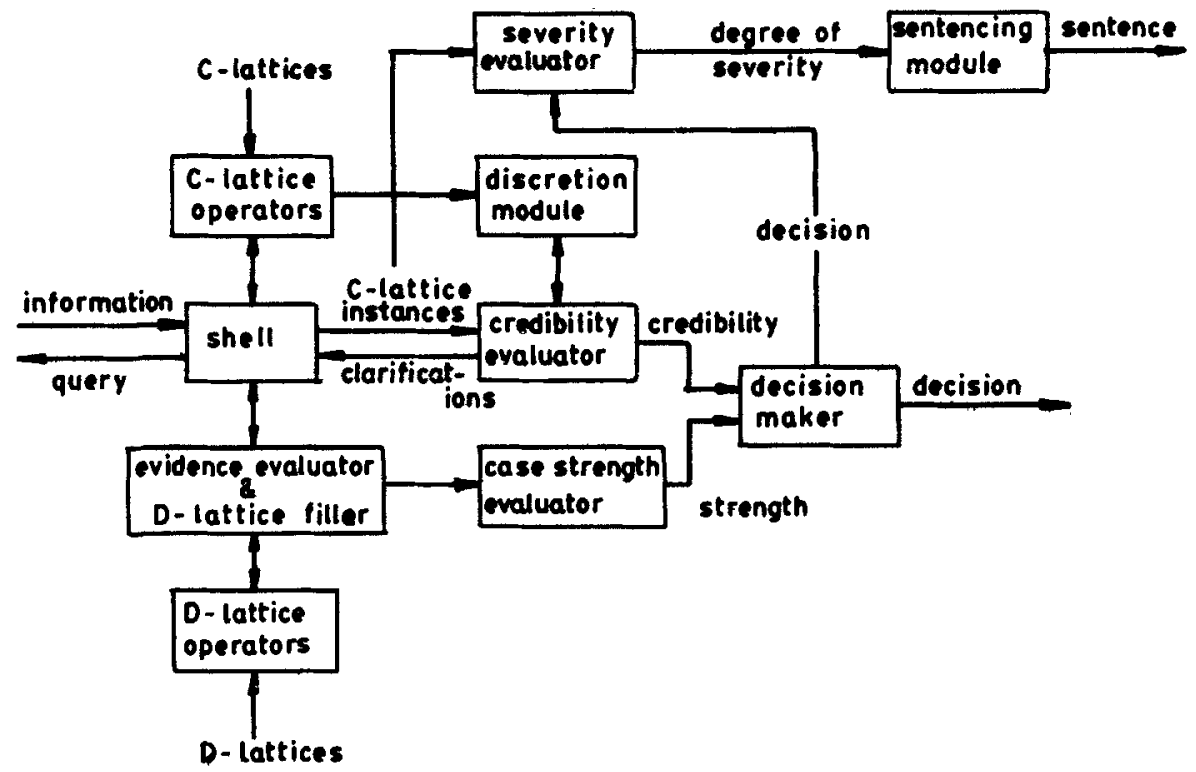

Figure 1. Legal counselling system. 
(2) Nontechnical information or the real world information of the case, such as the details of how and why the crime was committed can be represented as instances of the corresponding commonsense lattices (C-lattice).

(3) Formal general information regarding the sentential details of each section is represented as a sentencing lattice (S-lattice) and it is of static nature.

When the user interacts with the system, the shell collects the case details through a question-answering session. The shell used the C-lattice instances to accomodate the details of the real world information of the present case. Evidence estimator \& $D$-lattice filler gets technical information of the present case from the shell, and prepares the D-lattice instance representing the case in view of the relevant section. Case strength evaluator evaluates the corresponding D-lattice instance to measure the strength of a given case in accordance with the statute. The discretion module accomodates the experience-based real world knowledge of legal professionals as nontechnical heuristics. Credibility evaluator applies these heuristics on the C-lattice instances of the case to determine the credibility of the case. Decision maker suggests a decision on whether the accused has to be convicted or not based on the combined effect of strength and credibility of the case.

The judgement of a case includes the decision whether to convict or not as well as the sentence to be undergone by the accused if necessary. If a decision to convict the accused is taken, the decision-maker enables the sentencing module. Severity evaluator processes the $\mathrm{C}$-lattice instances of the present case to get a severity measure of the crime committed. Based on this measure, punishment will be meted out to the accused in accordance with the sentential norms contained in the relevant S-lattice. According to the norms provided by the S-lattice and the severity of the present case, sentencing will be made by the sentencing module.

Since human reasoning is being simulated in a specific domain, the system becomes an expert system (Keller 1987) as its decision-prediction performance tends to that of a human expert. In any case, this system has been developed in an attempt to provide intelligent professional assistance to legal professionals and offers intelligent support to busy legal professionals while applying the regular domain specific techniques in case analysis so that they can concentrate better on critical aspects of cases. In this paper the processing of nontechnical knowledge to estimate the credibility of a case is dealt with in detail.

\section{Knowledge structuring}

Nontechnical knowledge of a case involves information regarding the details of the crime. This knowledge should be organised as a hierarchical system so that the details of higher level objects can be elaborated at lower levels. A highly accepted knowledge structure that can represent a complex object as a hierarchical system is FRAME (Rich \& Knight 1991).

\subsection{Frames}

Frames are one of the highly accepted knowledge representational formalisms in the field of $\mathrm{AI}$, in particular in computer vision and natural language understanding. $A$ frame represents a complex stereotypical object/occurrence and its slots represent the stereotypical aspects of the object. A slot can contain another frame or an atom as 
its value at any of its various associated facets. The facets act as directives to the inferencing mechanism. An instance of a frame represents a specific object/occurrence and each of its slots can accomodate the particulars of the associated aspect of the specific object. In case of the absence of an aspect in an instance frame, it can inherit that aspect from its class frame. In case of the absence of an aspect in a class frame, it can inherit that aspect from its nearest ancestor. This value inheritance (Tichy 1987) property allows frames to avoid redundancy and to be concise. The value inheritance property makes the frames suitable for natural language understanding etc., where implicit knowledge retrieval is essential. The proposed legal system does not need the value inheritance since all individual facts of the case should be established explicitly. At the stage of predicting/making judgement the legal domain is a closed world and no attempts to establish the missing facts are allowed. Hence, the procedural attachment feature of frames in terms of demons etc. is also not necessary. Rather, the hierarchical knowledge structuring aspects of the frame suggest a new knowledge structure called LATTICE to represent the informal knowledge of legal domain.

\section{$3: 2$ LATTICE}

A class of objects/occurrences with a predefined set of attributes can be represented as a lattice. The specific information regarding a particular object/occurrence can be represented as an instance of the class lattice. The values of an attribute of the instance lattice can be filled, if and only if the corresponding class lattice supports that attribute (i.e. if it is a relevant attribute). Instead of unidimensional attributes, the lattice has two-dimensional attributes for the following benefits.

(1) Two-dimensional attributes make the lattice more expressive and nearer to the natural way of representing legel information.

(2) Due to the modularity derived by the two-dimensional attribute lattice, it is preferred by domain/legal experts. Hence, knowledge acquisition is convenient.

(3) a. Conversion of the domain expert's knowledge into internal knowledge structures is simpler for the knowledge engineer.

b. Checks for completeness and making modifications to the existing knowledge are more convenient due to the modularity.

The value of an attribute of an instance lattice can either be an atomic value or an instance of another lattice as dictated by the nature of the attribute.

3.3a Knowledge representation: Nontechnical information of a case involves details of the case in layman's view. This knowledge can be represented using various C-lattices. The set of C-lattices to represent theft cases are as follows.

(a) Case-Ref: This lattice is at the topmost level in the lattice system. This has to be accessed by the reference number of the case.

(b) Accused-name: This lattice gives the details of the accused in this case. All relevant known information of the accused should be filled into various attributes of this lattice.

(c) Execution-Ref: This lattice accomodates the details of the committment of the crime. These details are in turn structured into the three lattices-event-no, abetters-name, item-name.

(d) Event-no: This lattice represents the details of a particular event such as when and where the event happened: 


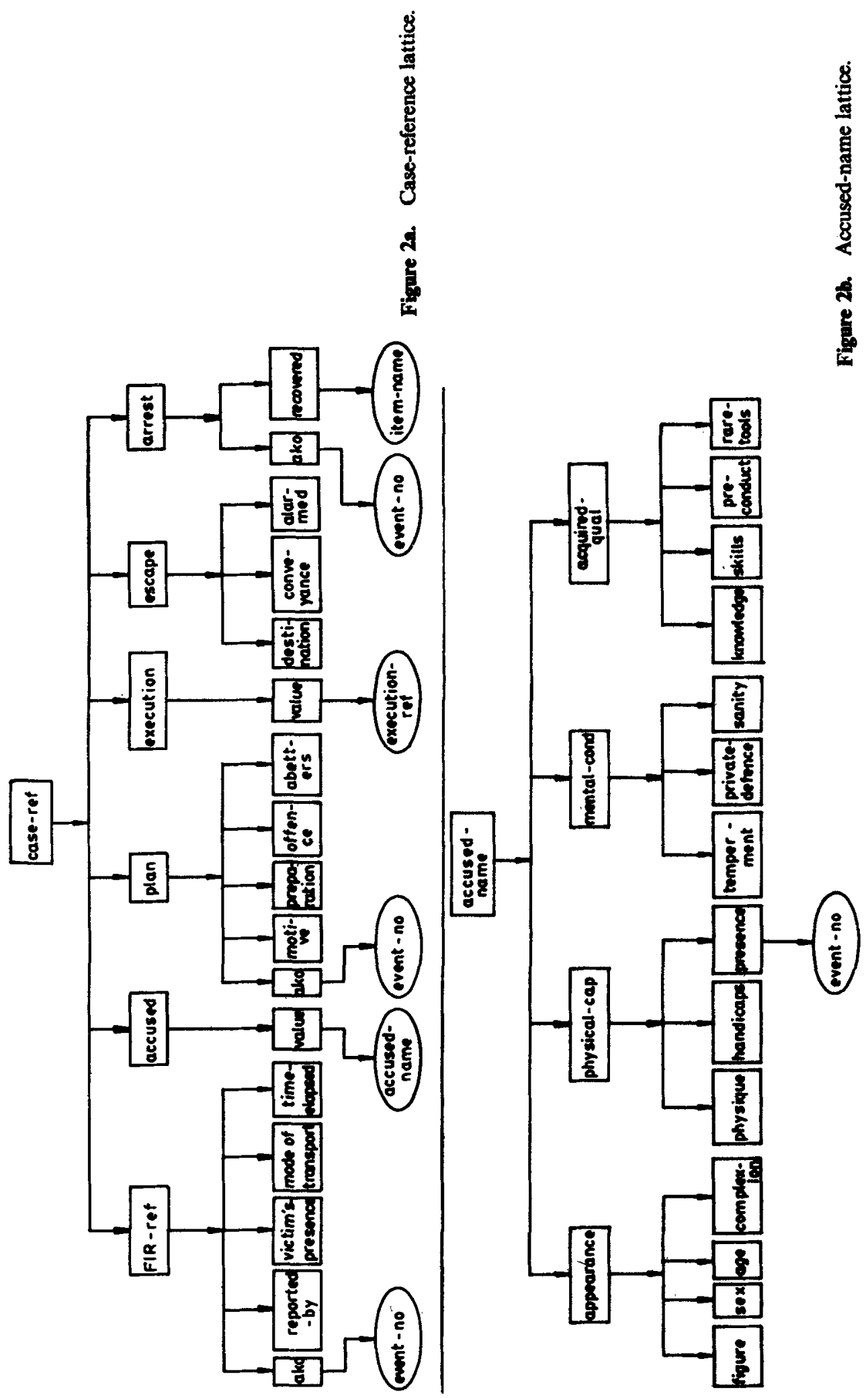




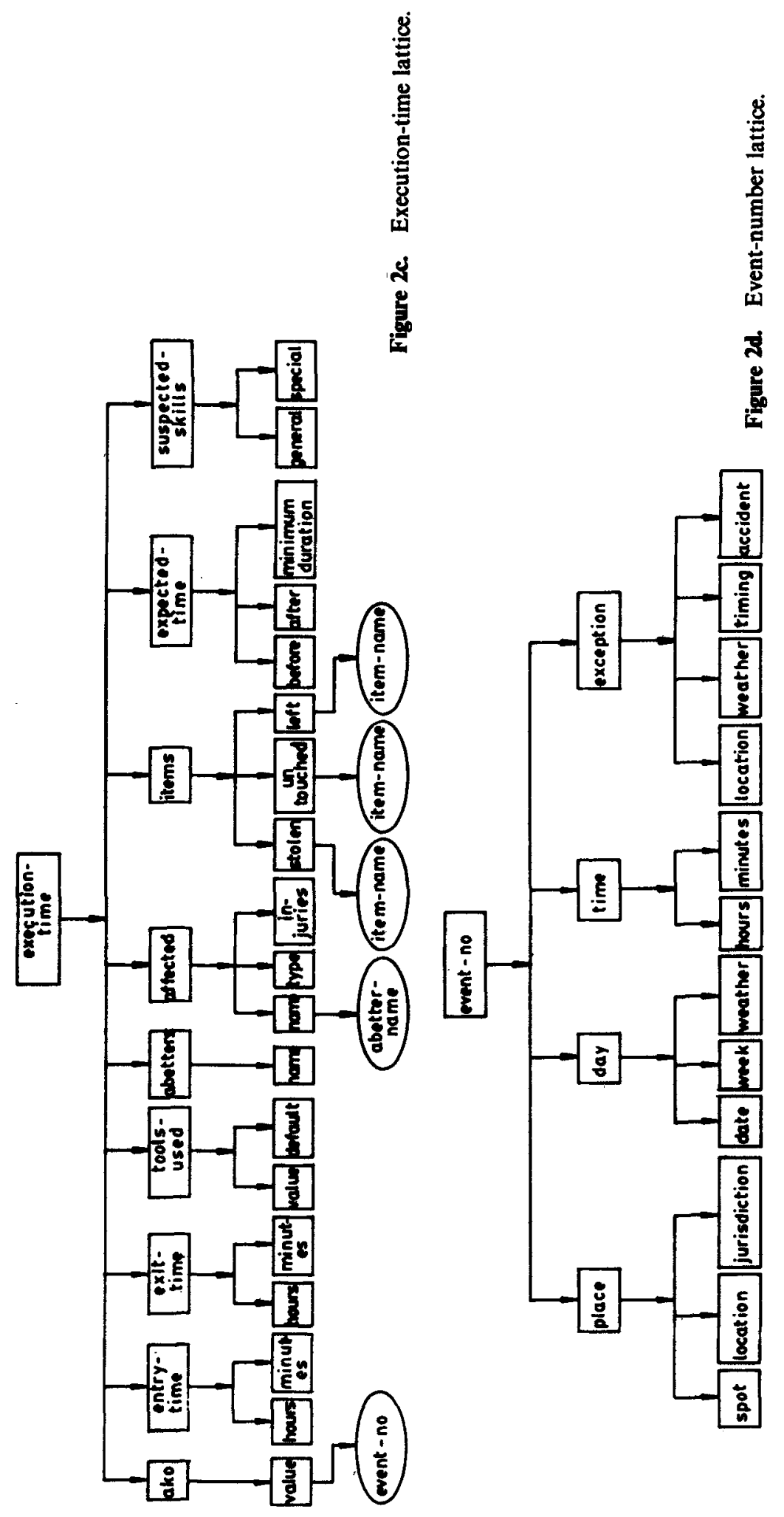



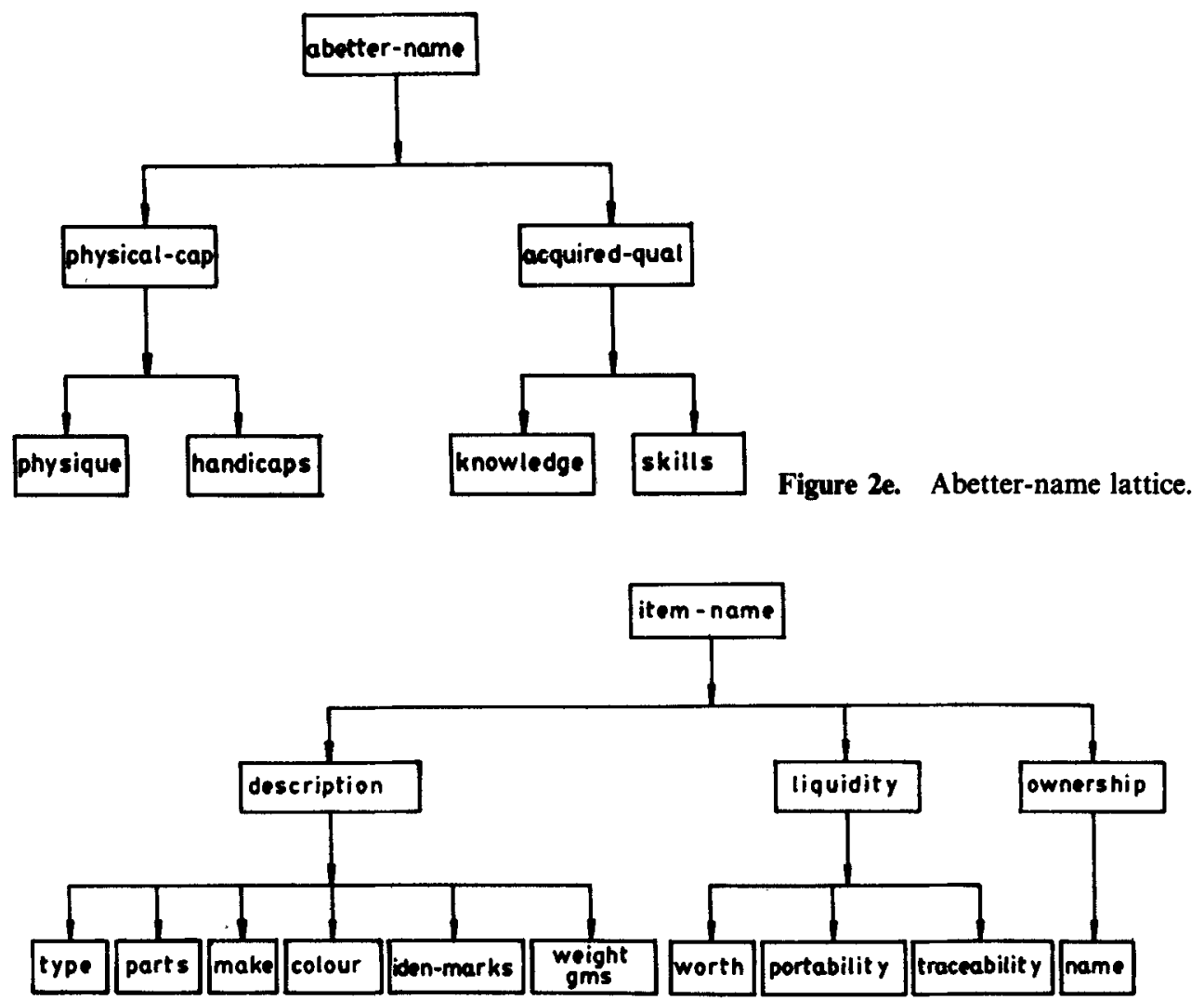

Figure 2f. Item-name lattice.

(e) Abetter-name: This represents the relevant capabilities of the abetters of the case.

(f) Item-name: It represents the characteristics of a particular item of interest.

These C-lattices are depicted as shown in figure 2.

3.3b C-lattice operators: C-lattices provide the structure for organising the real world/nontechnical knowledge of a particular case. Each of these provides a general structure for a chunk of relevant nontechnical knowledge. Several functions were developed in Common-LISP to operate with these lattices. The operations needed to store and retrieve the details of a case are as follows:

(1) (Intro-instance $\langle$ ref-no > case-ref): This function generates an instance of case-ref lattice and identifies it with $\langle$ ref-no $\rangle$.

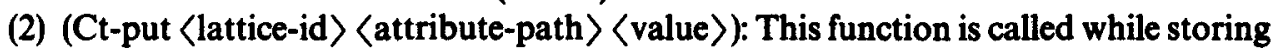
the details of a case. The value of the detail is stored in the identified lattice at the location according to the (attribute-path〉. While storing, the function checks the relevancy of the attribute-path. Automatic introduction of the value as an instance of its compatible lattice is done through this function.

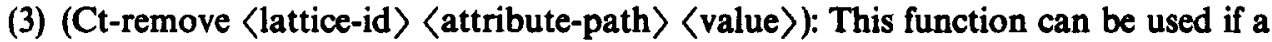
particular value of an attribute is found to be wrong and has to be deleted. The value will be deleted from the list of values of the attribute of the identified lattice. 


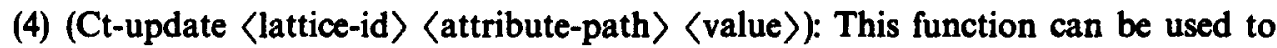
overwrite the previous value of an attribute with a new value. When this function is called the 〈value > will be stored as a single value of 〈attribute-path〉 of the $\langle$ lattice-id $\rangle$.

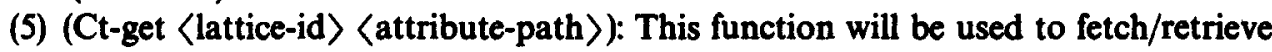
the list of values of (attribute-path> of lattice identified.

(6) (Ct-removelatt 〈lattice-id〉): This function can be used to delete lattices that were introduced as sub-structures to the lattice-id in a cascaded way. This function will be of use in cases of withdtawal of a case or cases that are finalised.

\subsection{Discretion module}

C-lattice instances associated with a case can be processed with the discretion module to evaluate the credibility of the case. The discretion module consists of heuristic knowledge of judges. This heuristic knowledge is represented procedurally over the C-lattice operators. Various chunks of heuristic knowledge are represented as individual 'rules' and a rule either supports or opposes the guilt of the accused. Some of the heuristics useful for dealing with theft cases have been implemented in our legal system. They are as follows.

\section{RULE 1}

IF

UNLESS all of them are explained reasonably

CONCLUDE to increase the credibility of the charge/commission of the offence of theft.
IF

UNLESS

CONCLUDE

RULE 3

IF

UNLESS

CONCLUDE to reduce the credibility of the case.

\section{RULE 4}

IF valued items

OR

OR

the untouched items are easily traceable

to reduce the credibility of the case. abetter

the accused takes away less valuable items apparently leaving high

there is a threat of being captured on the spot

the portability of the stolen item is more than that of items untouched

the accused who is old/child/female forced the stronger victims

the accused is supported by a strong weapon or a chemical or an 
UNLESS journey by any viable fast transport makes it possible to reach the destination within the stipulated time

AND

the accused is healthy and capable of doing such a journey

CONCLUDE to make the credibility of the case zero.

RULE 5

IF

the accused is not sound physically/mentally at the time of commission of the crime

UNLESS the experts certify his capability to perform all the required skills to commit the crime

OR

abetters can help him with those skills

CONCLUDE to reduce the credibility of the case to a greater extent.

RULE 6

IF

time elapsed between entry and exit of the accused into the crime scene is less than the minimum expected duration of crime

UNLESS with the support of a familiar abetter or the accused himself is familiar with the scene of crime

CONCLUDE to make the credibility of the case zero.

RULE 7

IF

the accused acquired/prepared a rare tool or vehicle that was used/suspected to be used while executing the crime

UNLESS he lost it well before the occurrence of crime

CONCLUDE to increase the credibility of the case to a greater extent.

RULE 8

IF

UNLESS

the accused did not acquire the required special skills

the skilled abetters helped him

OR

an effective preparation to take care of the situation is recorded

CONCLUDE to reduce the credibility of the case.

\section{RULE 9}

While comparing the recovered items with the stolen items

(a) IF

UNLESS

CONCLUDE

(b) IF

CONCLUDE some recovered items were found identical in all aspects to the stolen items

the accused proves his right of possession/ownership on all those items

to increase the credibility of the case

all recovered items differed from the stolen items in one way or the other

to reduce the credibility of the case. 


\section{Credibility evaluator}

Credibility is a positive real number associated with each case to represent the 'believability' of the case. For the sake of unbiased evaluation, the credibility of the case should be initialised to unity which neither supports nor opposes the guilt of the accused prior to evaluation. Then credibility evaluator selects the applicable discretion rules and executes them in an order dictated by the offence involved. In this process, the credibility of a case may increase/decrease in accordance with the execution of rules that support/oppose the guilt of the accused. The resultant credibility will be returned as a real number. If the resultant credibility is more than unity the accused is more likely to be convicted and if it is less than unity he may be acquitted. Credibility suggests the judgement in view of nontechnical information of the case. A sample session with credibility evaluator is given in appendix B.

\section{Conclusions}

Computer-based legal systems have to progress a long way to aid legal reasoning rather than legal information retrieval. The existing legal consultation systems are aimed at certain specific civil cases and a few of these systems attempt criminal cases. The distinctive features of criminal cases as against civil cases is the increased effectiveness of nontechnical matters in reaching the judgement. In this paper a model of a judgement prediction system has been proposed. This model aims at analysing a specific criminal case through technical as well as nontechnical perspectives and accordingly suggest the judgement. Co-accused cases are not considered in the present model. The components of the model to analyse the case through nontechnical perspectives are implemented in Common-LISP on the APOLLO, NEXUS 3500 under aegis. Though the subsystem developed is limited to handling theft cases, it can be extended to most other criminal cases.

The authors would like to thank Prof P V Ratnam, of the Department of Electrical Engineering for providing the APOLLO, NEXUS 3500 system. The first two authors benefited from stimulating discussions with Mr. C N V D Sastry, an advocate.

Appendix A. Glossary of terms.

Accused: a person against whom a case is filed in a criminal court;

Acquittal: decision by the court after finding the accused not guilty;

Conviction: decision by the court after finding the accused guilty;

Defendant: one who defends himself in a court of law;

Ingredient: an essential requirement;

Plaintiff: one who initiates (files) a case in a civil court;

Precedent: a binding case;

Section: a provision in a statute;

Sentencing: order imposing punishment by the judge;

Statute: an act passed by the legislature duly assented. 
Appendix B. Sample sessions.

Nontechnical information processing to estimate the credibility of theft cases is illustrated through the following sample session with the system.

\section{Case-1}

Description of the case-1

On 29th June, 1992, Monday, at around $2.30 \mathrm{a} . \mathrm{m}$. a theft occurred in the house of Sri Ramesh, situated at Lawsons Bay, Visakhapatnam. While the inmates were sleeping the accused entered the house through a ventilator with a rope, while an abetter waited outside the house. The accused threatened the inmates with a sharp knife and stole a gold chain worth Rs. $10,000 /-$ weighing $30 \mathrm{~g}$, a gold ring worth Rs. $3,000 /$ - weighing $10 \mathrm{~g}$ bearing the identification mark ' $\mathrm{Th}$ ' on it, and cash equal to Rs. 5,000/-. When the watchman (gurkha) approached the house, the abetter heard him, signalled to the accused through a window and both of them escaped. Four silver plates worth Rs. $16,000 /-$ weighing $2000 \mathrm{gms}$. were left untouched. Two days later, Pal and Raheem were arrested in Kakinada while they were trying to sell a gold chain (weighing $29 \mathrm{~g}$ ) and a ring (weighing $10 \mathrm{~g}$ ) which were similar to the stolen articles. The victims of the offence recognised Pal as the offender. It was found that the rope left at the scene of the crime was bought by $\mathrm{Pal}$ two days prior to the day of the crime. The accused Pal (30) is a strong man. Though he is dumb and deaf, he is skilled in climbing heights with a rope. The abetter Raheem is skilled in liquidating gold articles.

C-LATTICES REPRESENTING CASE-1 :

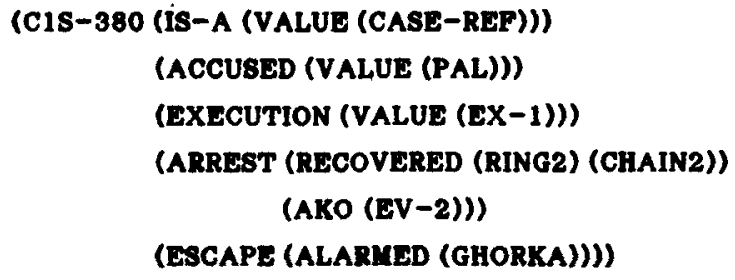


(SUSPECTED-SKILLS (GENERAL (RUNNING))

(SPECIAL (CLIMBING-WITH-ROPE)

(LIQUIDATING-GOLD)))

(AFPECTED (TYPE (MALE) (FEMALE)))

(ITEMS (STOLEN (CHAINI)

(RING1)

(CASH1))

(UNTOUCHED (SILVER-PLATES))

(LEFT (ROPEI))))

(EV-1 (IS-A (VALUE (EVENT-NO)))

(PLACE (SPOT (DTELLI NG-HOUSE))

(LOCATION (LATBONS-BAY))

(JURIBDICTION (VISAKHAPATNAY)))

(DAY (DATE (29-6-92))

(TEMK (MONDAY)))

(TME (HOURS (2))

(MINUTES (30))))

(CHAIN1 (IS-A (VALUE (ITEY-NAME)))

(DESCRIPTION (TYPE (ARNAMENT))

(MAKE (GOLD-90))

(WEIGHT-GKS ((30 0.96))))

(LIQUIDITY (TORTH (10000))

(PORTABILITY (VERY-HIGH))))

(RING1 (IS-A (VALUE (ITEM-NAME)))

(DESCRIPTION (TYPE (ARNAMENT))

(MAKE (GOLD-90))

(WEIGHT-GMS ((10)))

(IDEN-MARKS (TH)))

(LIQUIDITY (WORTH (3000))

(PORTABILITY (VERY-HIGH))))

(CASHI (IS-A (VALUE (ITEM-NAME)))

(LIQUIDITY (WORTH (6000))

(PORTABILITY (HIGH)))

(DESCRIPTION (TYPE (MONEY))))

(SILVER-PLATES (IS-A (VALUE (ITEM-NAME)))

(LIQUIDITY (PORTABILITY (MEDIUM))

(TORTH (16000)))

(DESCRIPTION (WEIGHT-GMS (2000)))) 


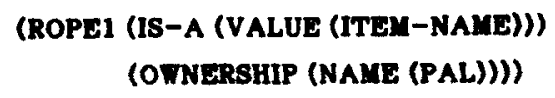

CASE 1. Evaluation follows in context 1.

$>$ (evaluate' C1S-380)

ROPE 1 belonging to accused was found at the scene of occurrence.

Is this reasonably explained?

Indicate $\mathbf{y} / \mathbf{n}$. $\mathbf{n}$

Does the deformity (DUMB-AND-DEAF) allow the accused to perform EACH and EVERY ONE of the following tasks (even with the help of RAHEEM)?

(RUNNING, CLIMBING-WITH-ROPE)

Consult the experts and accordingly indicate $y / n$. $y$

It is assumed that the weight of RING 1 is exact.

Did the accused prove his ownership/right of possession regarding each of the following items?

(CHAIN 2, RING 2)

Please indicate $\mathbf{y} / \mathbf{n}$. $\mathbf{n}$

1.5625 is the value of credibility for the present case C1S-380.

THANK-YOU!

CASE 1. Evaluation follows in context 2.

$>$ (evaluate' C1S-380)

ROPE 1 belonged to accused was found at the scene of occurrence.

Is this reasonably explained?

Indicate $y / n$. $y$ 
Does the deformity (DUMB-AND-DEAF) allow the accused to perform EACH and EVERY ONE of the following tasks (even with the help of RAHEEM)?

(RUNNING, CLIMBING-WITH-ROPE)

Consult the experts and accordingly indicate $y / n$. y

It is assumed that the weight of RING 1 is exact.

Did the accused prove his ownership/right of possession regarding each of the following items?

(CHAIN 2, RING 2)

Please indicate $\mathbf{y} / \mathbf{n} . \quad \mathrm{y}$

1 is the value of credibility for the present case C1S-380.

THANK-YOU!

\section{CASE 2}

\section{Description of case 2.}

On 2nd August, 1992, Sunday, at 8.15 p.m. a theft occurred in the house of Reddy, situated at Banjara Hills, Hyderabad. Reddy returned from his office with a briefcase containing one lakh rupees in his blue Maruti-92 car. After he relaxed for 5 minutes he found that a man of 25 years was driving away in his car and immediately noticed that the briefcase containing the cash was missing. Through investigation it was found that Geetha, the maid servant in the house, had dropped the briefcase and the car keys to help the accused. Three days later, one Rao was arrested with a similar red Maruti car in Warangal. The accused produced an alibi showing evidence that he was consulting a doctor in Tata Hospital, Bombay, on the day of the theft at 5.30 p.m.

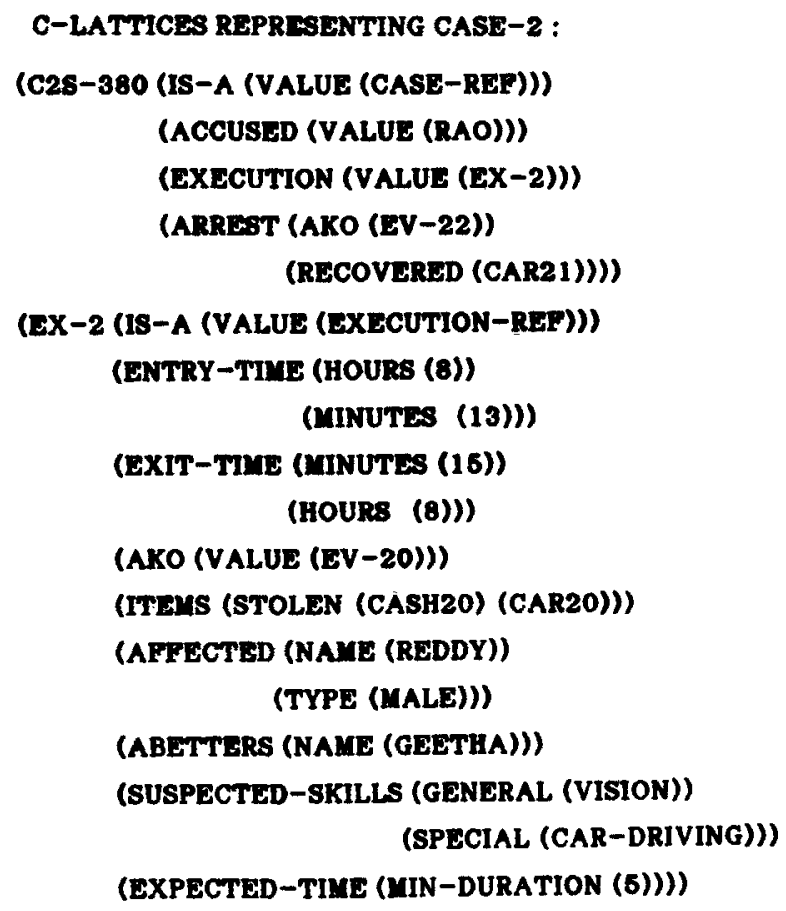




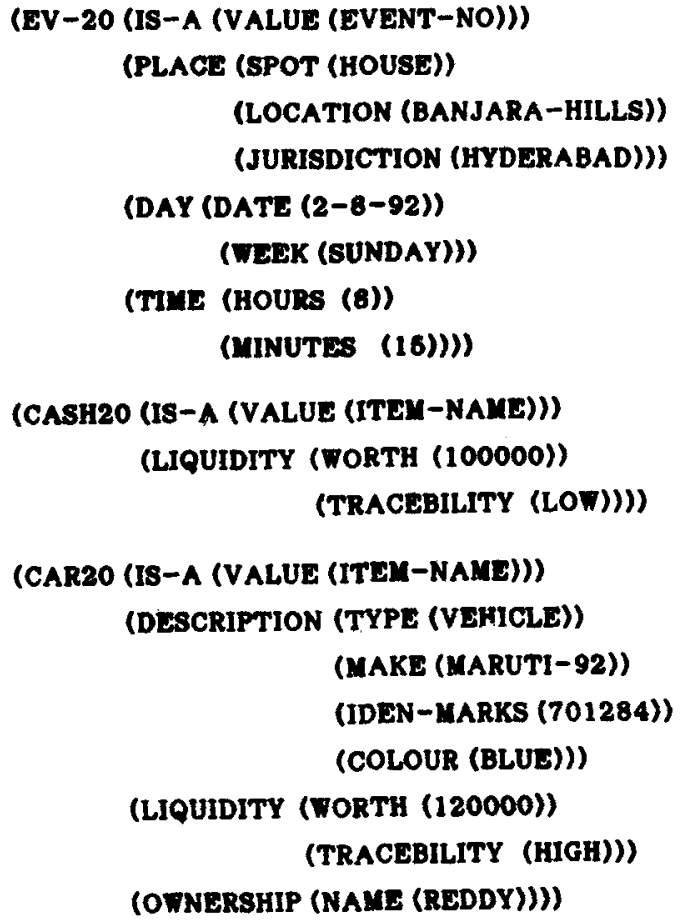

(CAR21 (IS-A (VALUE (ITEM-NAME)))

(DESCRIPTION (TYPE (VEHICLE))

(LAKE (MARUTI-92))

(IDEN-MARKS (701284))

(COLOUR (RED))))

(EV-22 (IS-A (VALUE (EVENT-NO)?)

(PLACE (JURISDICTION (WARANGAL)))

(DAY (DATE (5-8-92)))) 
CASE 2. Evaluation follows in context 3.

(>evaluate' C2S-380)

What is the distance in kilometres between HYDERABAD and BOMBAY?

750

Can the accused fly between HYDERABAD and BOMBAY?

Indicate $\mathbf{y} / \mathbf{n}$. $y$

Check whether a flight took off at BOMBAY on 2-8-92 after 6'O clock and reached HYDERABAD before 8.

Please indicate $\mathbf{y} / \mathbf{n} . \mathbf{n}$

C2S-381 INVALID

The court believes the alibi is reasonable.

0 is the value of credibility for the present case C2S-380.

THANK-YOU!

CASE 2. Evaluation follows in context 4.

$>$ (evaluate C2S-380)

What is the distance in kilometres between HYDERABAD and BOMBAY?

750

Can the accused fly between HYDERABAD and BOMBAY?

Indicate $y / n$. $y$

Check whether a flight took off at BOMBAY on 2-8-92 after 6'O clock and reached HYDERABAD before 8.

Please indicate $\mathbf{y} / \mathbf{n}$. $\mathbf{y}$

Is there a possibility to change the colour of CAR 21 ?

Indicate $y / n$. $y$

Did the accused prove his ownership/right of possession regarding each of the following items?

(CAR 21)

Please indicate $\mathbf{y} / \mathbf{n}$. $\mathbf{n}$

1.25 is the value of credibility for the present case C2S-380.

THANK-YOU!

\section{References}

Ashley K D 1991 Reasoning with cases and hypotheticals in HYPO. Int. J. Man Machine Studies 34: 753-796

Ashley K D, Rissland E L 1988 Dynamic assessment of relevancy in a case-based reasoner. Proceedings of the Fourth Conference on Artificial Intelligence Applications, California. pp. 208-214 
Gardner A L 1987 An artificial intelligence approach to legal reasoning (ed.) Bradford Book (Cambridge, MA: The MIT Press)

Hafner C D 1987 Conceptual organisation of case law knowledge bases. Proceedings of the First International Conference on AI and Law (New York: ACM)

Keller R 1987 Expert system technology: Development and application (Englewood Cliffs, NJ: Prentice-Hall)

McCarthy T 1980 The TAXMAN Project: Towards a cognitive theory of legal argument. Computer science and law: An advanced course (ed.) B Niblett (New York: Cambridge University Press)

Mehl L 1958 Automation in the legal world. Proceedings of Symposium on Mechanisation of Thought Processes (Teddington, London: Natl. Phys. Lab.)

Rich E, Knight K 1991 Artificial intelligence 2nd edn (New Delhi: Tata McGraw-Hill)

Srivastava S K 1991 Case-based systems in law: A survey. Project report, Department of Electronics, New Delhi

Tichy W F 1987 IEEE Comput. 20(11): 43-54 